\title{
Transcatheter valve implantation in a failed homograft
}

\author{
Andreas Habertheuer ${ }^{1}$, Morgan T. Harloff ${ }^{1}$, Musa A. Sharkawi ${ }^{2}$, Piotr S. Sobieszczyk ${ }^{2}$, Ashraf A. Sabe ${ }^{1}$, \\ Pinak B. Shah ${ }^{2}$, Tsuyoshi Kaneko ${ }^{1}$ \\ ${ }^{1}$ Division of Cardiac Surgery, Department of Surgery, Brigham and Women's Hospital, Harvard Medical School, Boston, Massachusetts, USA; \\ ${ }^{2}$ Division of Cardiology, Department of Medicine, Brigham and Women's Hospital, Harvard Medical School, Boston, Massachusetts, USA \\ Correspondence to: Tsuyoshi Kaneko, MD. Division of Cardiac Surgery, Brigham and Women's Hospital, 15 Francis Street, Boston, MA 02115, USA. \\ Email: tkaneko2@bwh.harvard.edu.
}

Submitted Apr 30, 2021. Accepted for publication Aug 09, 2021.

doi: 10.21037/acs-2021-tviv-18

View this article at: https://dx.doi.org/10.21037/acs-2021-tviv-18

\section{Clinical vignette}

We present a 70-year-old male with chronic heart failure and complex history including bicuspid aortic valve complicated by acute Type A aortic dissection requiring mechanical aortic valve (AV) and hemiarch replacement in 2001. In 2009, he returned with an aortic root abscess and moderate paravalvular leak (PVL) requiring reoperative aortic root replacement with a $26 \mathrm{~mm}$ homograft.

He now presents nine years after his second surgery with New York Heart Association class III symptoms. Transthoracic echocardiogram (TTE) revealed a failing aortic root homograft with moderate-to-severe aortic insufficiency (AI), moderate mitral regurgitation and a diffusely hypokinetic left ventricle (LV), ejection fraction $40 \%$. Coronary angiography demonstrated $40 \%$ left anterior descending, $70 \%$ right coronary and $70 \%$ posterior descending artery lesions. He was referred for transcatheter aortic valve replacement (TAVR). Society of Thoracic Surgeons Predicted Risk of Mortality score was $2.6 \%$; however, given the re-operative status he was deemed highrisk for surgical intervention.

\section{Surgical technique}

\section{Pre-TAVR workup}

A cardiac-gated computed tomography (CT) angiogram revealed minimal aortic root/leaflet calcification. Aortic annular area was $463 \mathrm{~mm}^{2}$, coronary ostia heights were $17.6 \mathrm{~mm}$ (left) and $22.7 \mathrm{~mm}$ (right). There was a residual
Type B dissection from the left subclavian to bilateral common iliac arteries.

\section{Exposure and access}

Under conscious sedation, common femoral artery (CFA) access was obtained with a $6 \mathrm{Fr}$ sheath via modified Seldinger technique using ultrasound and fluoroscopic guidance, and two Perclose ProGlide devices (Abbott Laboratories, Chicago, IL, USA) were preemptively deployed. The radial artery was accessed with a $6 \mathrm{Fr}$ sheath.

\section{Operation and valve deployment}

A $6 \mathrm{Fr}$ pigtail was advanced from the arterial sheath to the base of the right coronary sinus and a root aortogram obtained in co-planar view. A temporary pacing wire was advanced from the venous access. The 6 Fr CFA sheath was upsized to a $14 \mathrm{Fr}$ E-sheath, and an AL-1 catheter (Medtronic, Minneapolis, MN, USA) was advanced into the homograft aortic root. A straight wire was then advanced through the AL-1 and used to cross the homograft AV. The AL-1 was exchanged for a 6 Fr pigtail catheter and positioned in the LV apex. A Safari wire (Boston Scientific, Marlborough, MA, USA) was advanced into the LV. Based on CT sizing, we chose a $26 \mathrm{~mm}$ Edwards SAPIEN 3 Valve (Edwards Lifesciences, Irvine, CA, USA), which was advanced to the homograft aortic annulus. After confirming co-axial positioning, the SAPIEN 3 was deployed under rapid ventricular pacing with nominal volume, oversizing 
the annulus by $15 \%$.

Completion aortogram showed no significant PVL. TTE revealed a well-seated valve and excellent hemodynamics with a mean gradient of $13 \mathrm{mmHg}$ and trace PVL.

\section{Completion}

Hemostasis was achieved using the Perclose devices. The patient was discharged on post-TAVR day 7 .

\section{Follow-up and second TAVR}

The patient returned four months later with increasing dyspnea. TTE revealed severe PVL due to migration of the SAPIEN 3 towards the LV outflow tract with homograft leaflets visualized above the SAPIEN 3. The patient was placed under general anesthesia with transesophageal echocardiography (TEE) monitoring for a redo valvein-valve TAVR. Aortography confirmed migration and we proceeded to cross the valve and a larger $29 \mathrm{~mm}$ SAPIEN 3 under rapid ventricular pacing. The valve was deployed slightly higher in the annulus with $2 \mathrm{~mL}$ of extra volume in the delivery balloon to anchor the previous $26 \mathrm{~mm}$ SAPIEN 3, seal the area of PVL and prevent de-novo migration of the $29 \mathrm{~mm}$ SAPIEN 3. Intraoperative TEE revealed a well-seated valve with no evidence of PVL and a mean gradient of $10 \mathrm{mmHg}$.

Recovery was uneventful, with discharge on postTAVR day four. TTE at one-year follow-up confirmed a well-seated valve with excellent hemodynamics and evidence of only trace PVL and a mean gradient of $13 \mathrm{mmHg}$.

\section{Comments}

\section{Clinical results}

Reoperations in patients who have previously undergone homograft aortic root replacement may pose significant technical challenges and are associated with procedural mortality rates of up to $18 \%$ (1-3). While experience with valve-in-valve TAVR into failing stented and stentless nonhomograft bioprosthesis is growing, TAVR into failing homografts has limited data (3-5).

Duncan et al. (4) compared 1,598 patients undergoing TAVR into stented $(\mathrm{n}=1,307) v$ s. stentless $(\mathrm{n}=291)$ aortic bioprosthesis, including 77 homografts using the Valvein-Valve International Data (VIVID) registry. Authors noted a higher rate of device malpositioning $(10.3 \% v s$. $6.2 \%)$, subsequent need for second TAVR (7.9\% vs. 3.4\%), coronary obstruction (6.0\% vs. 1.5\%) and PVL for TAVR in stentless bioprostheses (4). Self-expanding devices were more frequently used in stentless bioprostheses (56\% vs. 39.9\%) (4). Thirty-day and one-year mortality were $6.6 \%$ and $15.8 \%$ for TAVR in stentless bioprostheses with no difference in mortality between non-homograft and homograft bioprostheses (4). Sedeek et al. (3) reported on 11 patients undergoing TAVR for failing homografts, majority of whom were treated with a SAPIEN 3 via transfemoral route. Mean aortic root annulus area was $512 \mathrm{~mm}^{2}$, and additional balloon volume was added in $55 \%$ of patients for a median transcatheter AV annulus oversize of 6\% (3). Thirty-day and one-year morality were $9 \%$ and $18 \%$ (3).

Our TAVR experience is currently limited to eight patients with failing aortic root homografts. [median age, 63; interquartile range (IQR), 56-73; 75\% male]. We approached all patients via transfemoral access with a balloon-expandable SAPIEN 3. Valve sizes ranged from 23-29 mm for annular areas of 295-654 $\mathrm{mm}^{2}$; median transcatheter AV annulus oversize was $15 \%$. Despite this, device malpositioning requiring valve-in-valve TAVR occurred in one patient and delayed valve migration occurred in one patient. Challenges of TAVR in homografts include lack of leaflet calcification leading to migration, AI resulting in poor visualization of the annulus and difficulty measuring the annular area. With careful planning and follow-up, we noted reassuring hemodynamics and no short-term or mid-term mortalities over a median followup of fifteen months.

Valve-in-valve TAVR for failing aortic root homografts may constitute an efficacious treatment option for otherwise highrisk surgical patients; however, larger series are warranted to understand and minimize specific procedural risks.

\section{Caveats}

Our experience highlights potential technical challenges: (I) distorted root architecture can make valve positioning and deployment difficult; we routinely use three pigtails marking the aortic cusps to establish co-planer view. (II) Mode of failure of aortic homografts is commonly AI with little leaflet calcification resulting in lack of adequate anchoring of transcatheter valves. Anchoring may be promoted by valve oversizing and adding additional volume to the delivery balloon. 


\section{Acknowledgments}

Funding: Departmental Funds.

\section{Footnote}

Conflicts of Interest: Dr. TK is a speaker for Edwards Lifesciences, Abbott, and Medtronic. Dr. PS is a speaker for Edwards Lifesciences. The other authors have no conflicts of interest to declare.

Open Access Statement: This is an Open Access article distributed in accordance with the Creative Commons Attribution-NonCommercial-NoDerivs 4.0 International License (CC BY-NC-ND 4.0), which permits the noncommercial replication and distribution of the article with the strict proviso that no changes or edits are made and the original work is properly cited (including links to both the formal publication through the relevant DOI and the license). See: https://creativecommons.org/licenses/by-nc-nd/4.0/.

Cite this article as: Habertheuer A, Harloff MT, Sharkawi MA, Sobieszczyk PS, Sabe AA, Shah PB, Kaneko T. Transcatheter valve implantation in a failed homograft. Ann Cardiothorac Surg 2021;10(5):717-719. doi: 10.21037/acs-2021-tviv-18

\section{References}

1. Jassar AS, Desai ND, Kobrin D, et al. Outcomes of aortic root replacement after previous aortic root replacement: the "true" redo root. Ann Thorac Surg 2015;99:1601-8; discussion 1608-9.

2. Di Eusanio M, Berretta P, Bissoni L, et al. Re-operations on the proximal thoracic aorta: results and predictors of short- and long-term mortality in a series of 174 patients. Eur J Cardiothorac Surg 2011;40:1072-6.

3. Sedeek AF, Greason KL, Nkomo VT, et al. Repeat aortic valve replacement for failing aortic root homograft. J Thorac Cardiovasc Surg 2019;158:378-385.e2.

4. Duncan A, Moat N, Simonato M, et al. Outcomes Following Transcatheter Aortic Valve Replacement for Degenerative Stentless Versus Stented Bioprostheses. JACC Cardiovasc Interv 2019;12:1256-63.

5. Dvir D, Webb JG, Bleiziffer S, et al. Transcatheter aortic valve implantation in failed bioprosthetic surgical valves. JAMA 2014;312:162-70. 